\title{
New Synthetic Applications of the Dithioacetal Functionality ${ }^{\dagger}$
}

\author{
TIEN-Yau LuH \\ Department of Chemistry, National Taiwan University, Taipei, Taiwan 10764, Republic of China \\ Received February 12, 1991 (Revised Manuscript Received July 31, 1991)
}

Functional-group transformations leading to carboncarbon bond formation are linchpins of synthetic endeavors. With the aid of transition-metal catalysts or reagents, the increasing numbers of new methodologies make the area highly fertile for synthetic surprise. A powerful addition to this arsenal includes the involvement of organosulfur compounds, the conversion of the carbon-sulfur bond(s) into carbon-carbon bond(s) being exceedingly useful., ${ }^{1,2}$ The dithioacetal has two carbon-sulfur bonds attached to the same carbon atom. As such, the sequential displacement of these two bonds can be very versatile in synthesis. This functional group was first described in $1885 .^{3}$ However, most frequently this functionality is confined to serve as a latent carbonyl or methylene group., Although the ridespread use of 2-lithio-1,3-dithiane as a carbonyl anion synthon is fascinating, ${ }^{6}$ the dithiane chemistry is still quite limited.

This Account reviews recent developments of synthetic applications of dithioacetals with respect to carbon-carbon bond formation. Three types of reactions are outlined in Scheme I. In the first instance, one of the carbon-sulfur bonds is replaced by a carbon-carbon bond, and subsequently the second carbon-sulfur bond is eliminated to produce an olefin. The second process involves replacement of both carbonsulfur bonds by carbon-carbon bonds, which results in geminal dialkylation. The third possibility concerns desulfurization leading to a possible carbene-like intermediate, which may dimerize to give an olefin. Other carbon-carbon bond forming reactions, such as alkylative desulfurization, and related chemistry will also be briefly covered.

\section{Nickel-Catalyzed Olefination Reactions}

Nickel-catalyzed cross-coupling reactions of aryl, allyl, and vinyl organosulfur compounds with Grignard reagents (eq 1) are very effective in carbon-carbon bond formation. 1,2,7 Simple aliphatic substrates, however,

$$
R^{1}-S-R^{2}+R^{3} M g X \stackrel{\text { cat. Ni(II) }}{\longrightarrow} R^{1} \cdot R^{3}
$$

are inert, and benzylic thioethers and mercaptans give poor yields of the coupling products. ${ }^{7}$ Our endeavor to expand the scope of the reaction resulted in the development of nickel-catalyzed olefinations of dithioacetals. ${ }^{8}$ Thus, styrenes have been obtained in 58-94\% yield (eq 2). This finding is a prototype of an olefination reaction from a dithioacetal functionality. Whereas cyclic ketone derivatives 1 give exclusively endocyclic

Tien-Yau Luh recelved a B.S. degree from National Taiwan University and a Ph.D. degree from the University of Chicago (with L. M. Stock). After spending two years as a postdoctoral associate at the University of Minnesota (with P. G. Gassman), he Joined the Chinese Untversity of Hong Kong in 1976 and returned to his alma mater in 1988, where he is currently Professor of Chemistry. His research interests include development of new synthetic methods using orcanometallic reagents, mechanistic organometallic chemistry, and chemistry of materials.

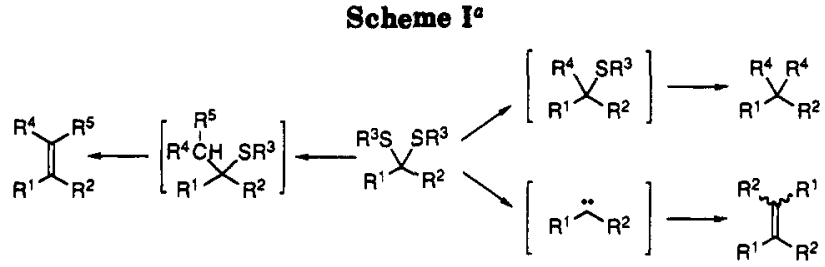

${ }^{a} \mathrm{R}^{1}=$ aryl or vinyl; $\mathrm{R}^{2}=\mathrm{H}$, alkyl, or aryl.

olefins 2 , the highly sterically hindered dithioacetal $1 \mathrm{c}$ produces 3 in $78 \%$ yield. Homologous straight-chain Grignard reagents in the presence of a nickel catalyst react with aryl aldehyde and diaryl ketone derivatives similarly (eq 3). ${ }^{8 b}$ Further extension of this reaction to orthothioesters provides a new route for the alkylative olefination of an ester equivalent (eq 4). ${ }^{9}$ Functional groups such as $\mathrm{RO}, \mathrm{F}, \mathrm{Me}_{3} \mathrm{Si}$, and $\mathrm{Me}_{3} \mathrm{Sn}$ on the aromatic ring in dithioacetals remain intact under the reaction conditions. The benzylic trifluoromethyl group, on the other hand, is transformed into an isopropene moiety. ${ }^{10}$

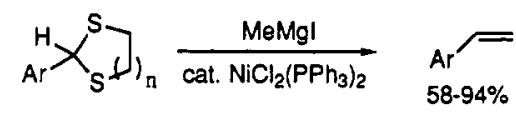
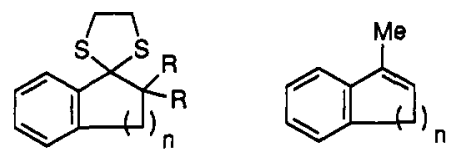

1a $R=H_{1} n=1$

b $R=H, n=2$

$2 a n=1$

$b n=2$

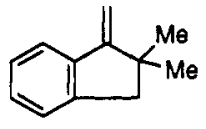

$C R=M e, n=1$

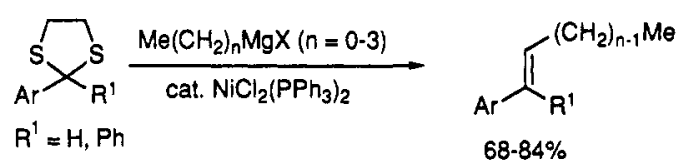

$$
R^{1}=\mathrm{H}, \mathrm{Ph}
$$
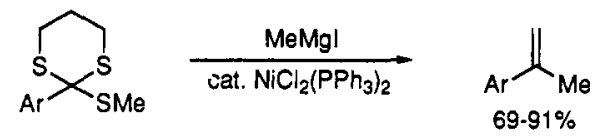

'Dedicated to Professor Yau-Tang Lin on the occasion of his 80th birthday, from whom the author first learned organic chemistry.

(1) Luh, T.-Y.; Ni, Z.-J. Synthesis 1990, 89.

(2) (a) Naso, F. Pure Appl. Chem. 1988, 60, 79. (b) Fiandanese, V. Pure Appl. Chem. 1990, 62, 1987.

(3) Baumann, E. Ber. Dtsch. Chem. Ges. 1885, 18, 883.

(4) Greene, T. W. Protective Groups in Organic Synthesis; Wiley: New York, 1981; p 129.

(5) Carey, F. A.; Sundberg, R. J. Advanced Organic Chemistry; 3rd ed.; Plenum: New York, 1990; Part B, p 266.

(6) For a recent review, gee: Page, P. C. B.; van Niel, M. B.; Prodger, J. C. Tetrahedron 1989, 45, 7643 and references therein.

(7) (a) Okamura, H.; Miura, M.; Takei, H. Tetrahedron Lett. 1979, 43. (b) Wenkert, E.; Ferreira, T. W.; Michelotti, E. L. J. Chem. Soc., Chem. Commun. 1979, 637.

(8) (a) Ni, Z.-J.; Luh, T.-Y. J. Chem. Soc., Chem. Commun. 1987, 1515. (b) Ni, Z.-J.; Mei, N.-W.; Shi, X.; Wang, M. C.; Tzeng, Y.-L.; Luh, T.-Y. J. Org. Chem. 1991, 56, 4035.

(9) (a) Tzeng, Y.-L.; Luh, T.-Y.; Fang, J.-M. J. Chem. Soc., Chem. Commun. 1990, 399 . (b) Weng, W.-W., unpublished results. 


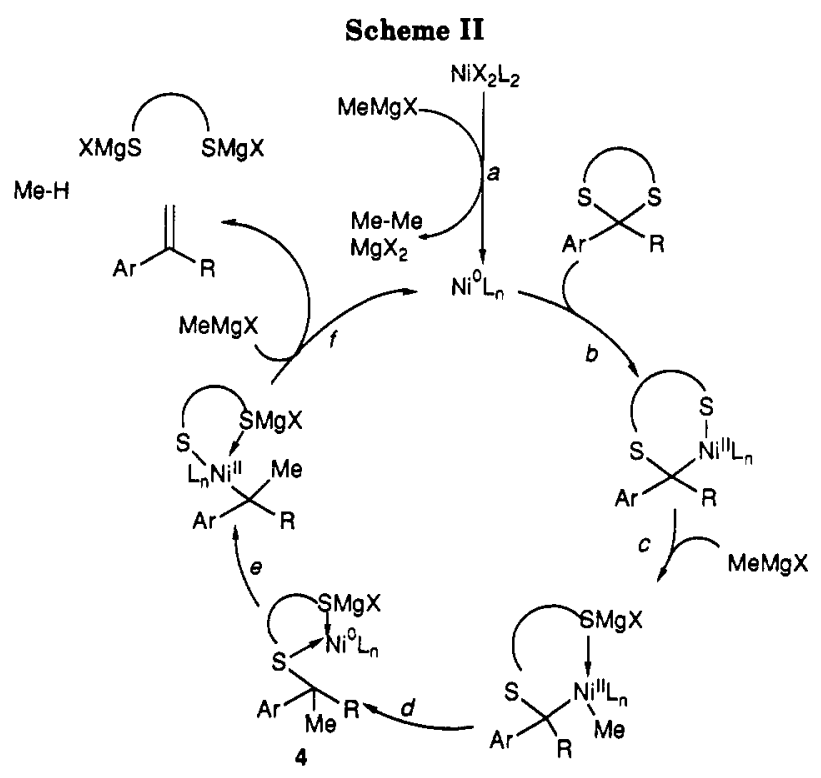

Aryl halides are expected to react under similar conditions (Kumada-Corriu reaction). ${ }^{11}$ Palladium is an active catalyst for the cross coupling of Grignard reagents with aryl halides, but not with dithioacetals. ${ }^{8 b}$ Accordingly, selective transformations have been achieved (eq 5), ${ }^{8 b}$

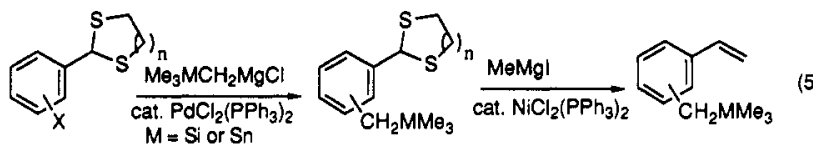

Mechanism. A plausible catalytic cycle for the nickel-catalyzed olefination of the dithioacetal with the Grignard reagent is presented in Scheme II. ${ }^{8}$ Several points about this catalytic cycle are worthy of comment. First, the active $\mathrm{Ni}(0)$ catalyst is generated in situ by the reduction of $\mathrm{NiCl}_{2}\left(\mathrm{PPh}_{3}\right)_{2}$ with the Grignard reagent (step a). ${ }^{8}$ Oxidative addition of this $\mathrm{Ni}(0)$ species with the dithioacetal (step b) and association of the Grignard reagent (step c) followed by reductive elimination (step d) afford intermediate 4. Further oxidative addition (step e) and $\beta$-elimination (step f) lead to the olefination product.

Secondly, the formation of the carbon-carbon bond precedes the elimination step, as clearly shown by the previous examples (eqs 2-5). In addition, treatment of 5 with $\mathrm{Me}_{3} \mathrm{SiCH}_{2} \mathrm{MgCl}$ gives the same product distribution ( 8 and 9 ) as that from the reaction of 6 with MeMgI (eq 6). 12a,13b A common intermediate 7 must therefore be involved in both reactions.

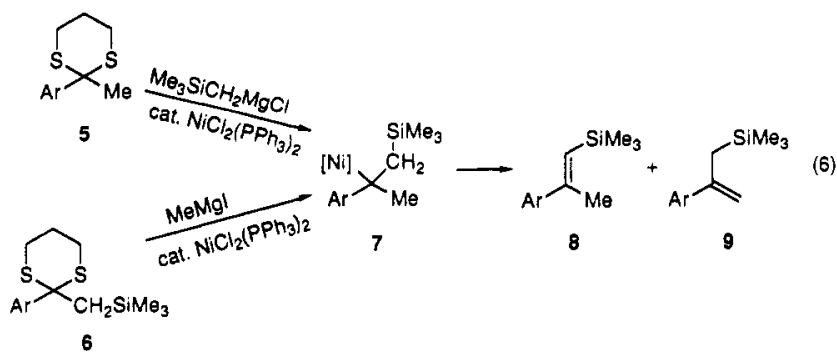

(10) Yu, C.-C., unpublished results.

(11) Kumada, M. Pure Appl. Chem. 1980, 52, 669

(12) (a) Ni, Z.-J. Dissertation, The Chinese University of Hong Kong, 1989. (b) Wang, M. C., unpublished results.

(13) (a) Ni, Z.-J.; Luh, T.-Y. J. Chem. Soc., Chem. Commun. 1988, 1101. (b) Wong, K.-T.; Ni, Z.-J.; Luh, T.-Y. J. Chem. Soc., Perkin Trans. 1 , in press.
Table I

Product Distribution of the Nickel-Catalyzed Reactions of Dithioacetals with $\mathrm{Me}_{3} \mathrm{SiCH}_{2} \mathbf{M g C l}$

\begin{tabular}{lcc}
\hline \multicolumn{1}{c}{$\mathrm{Ar}$} & $\begin{array}{c}\text { \% yield }(9 / 8) \\
\text { from substrate 11a }\end{array}$ & $\begin{array}{c}\text { \% yield (9/8) } \\
\text { from substrate 11b }\end{array}$ \\
\hline 2-fluorenyl & $72(90 / 10)$ & $91(32 / 68)$ \\
4-MeOC $\mathrm{M}_{6} \mathrm{H}_{4}$ & $85(73 / 27)$ & $78(14 / 86)$ \\
4- $\mathrm{MeC}_{6} \mathrm{H}_{4}$ & $77(86 / 14)$ & $73(22 / 78)$ \\
$4-\mathrm{PhC}_{6} \mathrm{H}_{4}$ & $81(89 / 11)$ & $73(34 / 66)$ \\
$3-\mathrm{MeOC}_{6} \mathrm{H}_{4}$ & $64(86 / 14)$ & $71(40 / 60)$ \\
$4-\mathrm{FC}_{6} \mathrm{H}_{4}$ & $85(80 / 20)$ & $78(32 / 68)$
\end{tabular}

Thirdly, a benzylic thioether intermediate 4 may be involved. Benzylic thioethers are generally quite unreactive toward Grignard reagents even at elevated temperatures. ${ }^{7,12}$ A possible scenario is that the cleavage of the remaining carbon-sulfur bond is facilitated by ligation of both sulfur atoms to nickel. The close proximity of the two sulfur atoms to each other apparently plays a part in the facile cleavage of both carbon-sulfur bonds during these nickel-catalyzed reactions. This phenomenon can be considered as a "sulfur tandem ancillary effect". To test the validity of this conjecture, the reactions of $10(n=2-4)$ with $\mathrm{MeMgI}$ at room temperature in the presence of the $\mathrm{NiCl}_{2}\left(\mathrm{PPh}_{3}\right)_{2}$ catalyst give the corresponding styrene in $60-70 \%$ yield (eq 7). ${ }^{12 b}$ On the other hand, when $n$ $=6,10$ is relatively unreactive, presumably due to the unfavorable formation of a nine-membered chelate. ${ }^{12 b}$ These observations indicate that the terminal mercapto group may participate in the reaction, and a similar process (i.e., nickel insertion of the $\mathrm{C}-\mathrm{S}$ bond, followed by $\beta$-elimination) is implied in the conversion of intermediate 4 into the product.

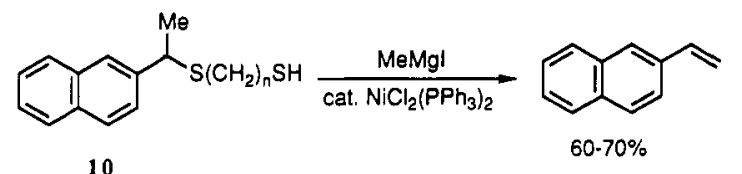

Fourthly, the reactions shown in eq 6 indicate that $\beta$-elimination of the organonickel intermediate $7 \mathrm{can}$ occur in two different directions to give 8 and/or $9 .{ }^{13}$ Interestingly, the ring size of the sulfur heterocycle in 11 affects the product distribution of the reactions (Table I), with five-membered dithiolanes 11a giving 9 predominantly, while six-membered dithianes $11 \mathrm{~b}$ favor 8. This discrepancy disappears with the nickel catalyst contains a bidentate ligand such as dppe. Examination of the possible intermediate 12 reveals that both sulfur atoms of a dithioacetal may coordinate to the nickel throughout the catalytic cycle such that the stereoelectronic requirement of the metallacycle in 12 may determine the orientation of $\beta$-elimination. ${ }^{13 \mathrm{~b}}$
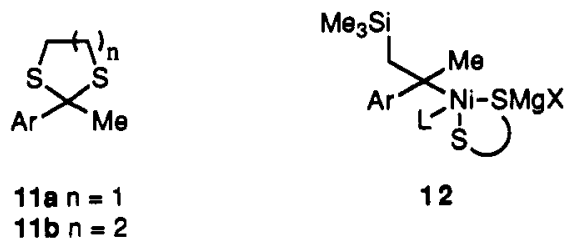

12

The fifth point concerning the catalytic cycle is the requirement of a second equivalent of the Grignard reagent for the elimination step (step f). The cross coupling of 13 with $i$-PrMgBr under the usual conditions gives, in addition to the desired olefin 14, the reduction product $15 .^{8}$ Cyclopentyl Grignard reagents 
react similarly. ${ }^{14}$ Intermediate 16 may undergo $\beta$ elimination competitively to give 17 and 18 . The latter may undergo reductive elimination producing 15 (eq 8 ).

$$
\text { (B) }
$$

Syntheses of Dienes. Cyclopropylcarbinyl organometallic compounds readily undergo ring opening to give homoallylmetal species, ${ }^{15}$ which may then be followed by a $\beta$-elimination leading to butadienes ${ }^{16}$ (eq 9 ). On the basis of the mechanism shown in Scheme II, when a cyclopropyl Grignard reagent is employed, intermediate 19 is expected. Thus, the rearrangement of 19 according to eq 9 represents a facile stereoselective synthesis of substituted butadienes $20 .{ }^{17}$

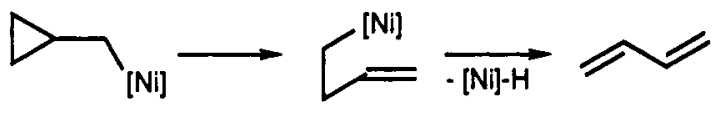<smiles>[2H]C([AlH2])([AlH2])C1CC1</smiles>

19

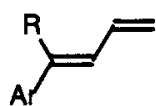

20

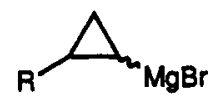

21
The reaction of dithioacetals with 2-substituted cyclopropyl Grignard reagents 21 depends on the nature of the substituent. When $R$ in 21 is an alkyl group, the reaction of 13 with 21 under the usual conditions yields a mixture of substituted butadienes 22 and 23 . The migration of the nickel atom and cleavage of the three-membered ring of intermediate 24 is nonselective. On the other hand, when $\mathrm{R}$ in $\mathbf{2 1}$ is an aryl group, regioselective rearrangement occurs and butadienes 23 are formed exclusively. ${ }^{10,14}$ The reaction products from the norcarene Grignard reagent are mixtures of 1,4- and 1,5-dienes (eq 10). ${ }^{17}$ The cyclobutyl analogue gives the normal cross-coupling product without ring opening. ${ }^{17,18}$

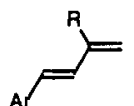

22

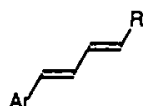

23

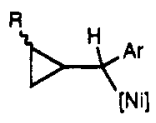

24

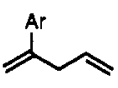

25
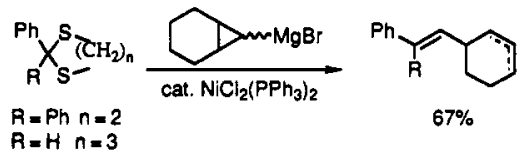

$67 \%$

(14) Ng, D. K. P., unpublished results.

(15) (a) Bullock R. M. Samsel, E. G.J. Am. Chem. Soc. 1987, 109, 6542. (b) Bullock, R. M.; Rappoli, B. J.; Samsel, E. G.; Rheingold, A. L. J. Chem. Soc., Chem. Commun. 1989, 261. (c) Donaldson, W. A.; Brodt C. A. J. Organomet. Chem. 1987, 330, C33. (d) Hill, E. A.; Park, Y.-W. J. Organomet. Chem. 1988, 356, 1. (e) Fournet, G.; Balme, G.; Gore, J. Tetrahedron Lett. 1987, 28, 4533. (f) Fournet, G.; Balme, G.; Gore, J. Tetrahedron 1988, 44, 5809. (g) Fournet, G.; Balme, G.; Barieux, J. J.; Gore, J. Tetrahedron 1988, 44, 5821.

(16) (a) Pinke, P. A. Stauffer, R. D. Miller, R. G. J. Am. Chem. Soc. 1974, 96, 422. (b) Salomon, R. G.; Salomon, H. F.; Kachinske, J. L. C. J. Am. Chem. Soc. 1977, 99, 1043. (c) Doyle, M. R.; van Leusen, D. J. Org. Chem. 1982, 47, 5326. (d) Sarel, S.; Langbeheim, M. J. Chem. Soc Chem. Commun. 1979, 73. (e) Sarel, S. Acc. Chem. Res. 1978, 11, 204 and references therein. (f) Chiusoli, G. P.; Costa, M.; Melli, L. J. Organomet. Chem. 1988, 358, 495.

(17) Ng, D. K. P.; Luh, T.-Y. J. Am. Chem. Soc. 1989, 111, 9119

The coupling reactions involving cyclopropyl Grignard reagents illustrate the first example using cyclopropyl anion as an allyl anion synthon from which substituted butadienes can be conveniently synthesized. Mechanistically, the isolation of butadienes further validates the proposed catalytic cycle as shown in Scheme II, namely, the carbon-carbon bond formation preceding the elimination process.

Reactions of dithioacetals 11 with allylmagnesium halides under the usual conditions provide a useful reference point to the reactions described above. Interestingly, 1,4-pentadienes 25 are the predominant, if not exclusive, products, and the conjugated diene 20 (R $=\mathrm{Me}$ ) is a side product only when sterically hindered 11 (e.g., $\mathrm{Ar}=1$-naphthyl or 2-tolyl) is employed. ${ }^{\mathrm{bb}}$

Syntheses of Vinylsilanes and Silylated Butadienes. Vinylsilanes and silylated butadienes have demonstrated an enormous variety of fascinating applications in organic synthesis. ${ }^{19}$ Although synthetic methodologies for these building blocks are numerous, the nickel-catalyzed coupling reactions have provided a unified stereoselective synthesis of different kinds of vinylsilanes 26-28 (56-91\% yield) and silylated butadienes 29-32 (65-97\% yield). ${ }^{20}$ In each olefin, the
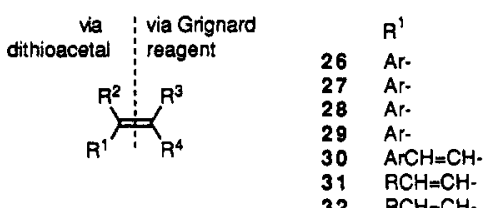

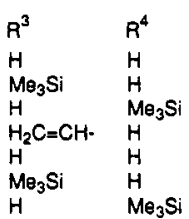

left-hand-side moiety is derivable from a dithioacetal whereas the Grignard reagent provides the righthand-side alkylidene moiety. The reaction is stereospecific, and only the $E$ isomer, whenever applicable, is obtained.

Bis(vinylsilanes) 33 and 34 are obtained in 80 and $69 \%$ yields, respectively, from the corresponding bis(dithioacetals) ${ }^{20}$ As mentioned earlier, aryl halides also react under the reaction conditions. ${ }^{11}$ Consequently, this reaction has been exploited for the one-step synthesis of 35 and 36, each of which has both a vinylic and a benzylic silyl group. ${ }^{20}$ Compounds like 35 would be very useful in annulation reactions. ${ }^{21}$

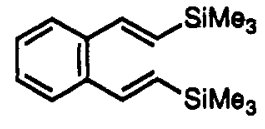

33<smiles>CC=Cc1ccccc1CSC</smiles>

35
34

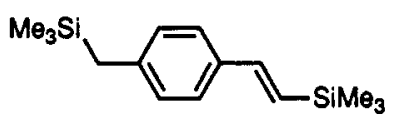

36

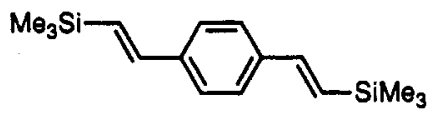

(18) Ring opening has been found in cyclobutylcarbinyl organometallic systems. Cf.: (a) Lehmkuhl, H.; Rufinska, A.; Benn, R.; Schroth, G.; Mynott, R. Liebigs Ann. Chem. 1981, 317. (b) Larock, R. C.; Varaprath, S. J. Org. Chem. 1984, 49, 3435 and references therein.

(19) For a recent review, see: Patai, S., Rappoport, Z., Eds. The Chemistry of Organic Silicon Compounds; Wiley: Chichester, 1989; Parts 1 and 2.

(20) (a) Ni, Z.-J.; Luh, T.-Y. J. Org. Chem. 1988, 53, 2129. (b) Ni, Z.-J. Yang, P.-F.; Ng, D. K. P.; Tzeng, Y.-L.; Luh, T.-Y. J. Am. Chem. Soc. $1990,112,9356$.

(21) (a) Sano, H.; Ohtsuka, H.; Migita, T. J. Am. Chem. Soc. 1988, 110 2014. (b) Ito, Y.; Nakatsuka, M.; Saegusa, T. J. Am. Chem. Soc. 1980, 102, 863. (c) Ito, Y.; Miyata, S.; Nakatsuka, M.; Saegusa, T. J. Org. Chem. 1981, 46, 1043. (d) Djuric, S.; Sarkar, T.; Magnus, P. J. Am. Chem. Soc. $1980,102,6885$. 
The reaction of an orthothioester with $\mathrm{Me}_{3} \mathrm{SiCH}_{2} \mathrm{MgCl}$ provides a facile synthesis of 37 which possesses both allyl- and vinylsilane functionalities (eq 11). ${ }^{9}$ The product 37 may serve as a 1,3-dianion synthon (38) or a 1,1 -dianion synthon (39). ${ }^{9 b}$<smiles>[Mg]C1([AsH2])SCCCS1</smiles>

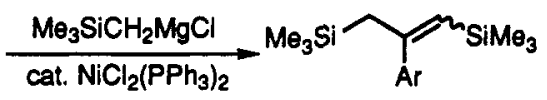

$37 E / Z=25-50 / 75-50$ $(48-79 \%)$<smiles>C=C(C)[AlH2]</smiles><smiles>C=C([18F])[AlH2]</smiles><smiles>[R]C=CC1SCCS1</smiles>
39

38 40

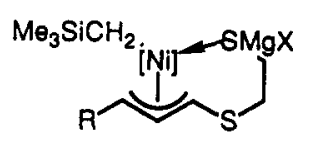

41
Allylic dithioacetal 40 has two possible sites ( $\alpha$ vs $\gamma$ positions) for coupling. While cross-coupling reactions of allylic geminal diacetates are generally nonselective, ${ }^{22}$ the sulfur moiety in the proposed intermediate $\mathbf{4 1}$ may have a directive effect such that the regiochemistry of the reaction could be controlled. Thus, the synthesis of 1-(trimethylsilyl)butadienes $31(R=$ alkyl or aryl) has been accomplished regio- and stereoselectively in 65-93\% yield. ${ }^{206,23}$ 1-(Trimethylsilyl)hexatriene 42 has been prepared from the corresponding dienyldithiolane similarly. ${ }^{20 b}, 23 \mathrm{~A}$ A vinylsilane can be converted to an $\alpha, \beta$-unsaturated aldehyde, ${ }^{24}$ which can in turn serve as the precursor of a higher homologue of the vinylsilane. Consequently, by employing these two methodologies, homologation of enals can be achieved. The reaction of orthothioester 43 with an excess amount of $\mathrm{Me}_{3} \mathrm{SiCH}_{2} \mathrm{MgCl}$ under the usual conditions afforded 44. ${ }^{20 b}$

The internal silyl dienes 30 can be prepared from the corresponding silylated dithioacetals 45 by reaction with MeMgI in the presence of a catalytic amount of $\mathrm{NiCl}_{2}\left(\mathrm{PPh}_{3}\right)_{2}{ }^{206}$ As will be discussed later, simple allylic dithioacetals yield under similar conditions the corresponding geminal dimethyl derivatives as the major product, and the more sterically hindered dithioacetals give predominantly butadienes. ${ }^{25}$ The exclusive formation of 30 must be due to the presence of the bulky $\mathrm{Me}_{3} \mathrm{Si}$ group in 45 . Similarly, the reactions of $45(\mathrm{R}=$ aryl) with $\mathrm{Me}_{3} \mathrm{SiCH}_{2} \mathrm{MgCl}$ give 32 in good yields stereospecifically. ${ }^{20 \mathrm{~b}}$ The reaction of the crotonaldehyde derivative $45(\mathrm{R}=\mathrm{Me})$ is worth noting, as none of the desired $32(\mathrm{R}=\mathrm{Me})$ is obtained. Instead, 46 is isolated as the sole product. It may be a consequence of steric control in the hydride elimination step that occurs preferably at the methyl carbon to give the more stable 46.

An approach to 1-aryl-1-(trimethylsilyl)butadienes 29 is based on the nickel-catalyzed coupling reaction of the

(22) (a) Wenkert, E.; Ferreira, T. W. Organometallics 1982, $1,1670$. (b) Lu, X.: Huang, Y. J, Organomet. Chem. 1984, 268, 185. (c) Trost, B. M.; Vercauteren, J. Tetrahedron Lett. 1985, 26, 131.

(23) (a) Ni, Z.J.; Luh, T.Y. J. Org. Chem. 1988, 53, 5582. (b) Ni, Z.-J.; Luh, T.-Y. Org. Synth., in press.

(24) (a) Chan T. H.; Lau, P. W.; Mychajlowskij, W. Tetrahedron Lett. 1977, 3317. (b) Pilot, J. P.; Dunogues, J.; Calas, R. Bull. Soc. Chim. Fr. 1975, 2143. (c) Yamamoto, K.; Nunokawa, O.; Tsuji, J. Synthesis 1977 721. (d) Yamamoto, K.; Yoshitake, J.; Qui, N. T.; Tsuji, J. Chem. Lett. 1978, 859. (e) Yamamoto, K.; Ohta, M.; Tsuji, J. Chem. Lett. 1979, 713

(25) (a) Yang, P.-F.; Ni, Z.-J.; Luh, T.-Y. J. Org. Chem. 1989, 54, 2261. (b) Tzeng, Y.-L.; Yang, P.-F.; Mei, N.-W.; Yuan, T.-M.; Yu, C. C.; Luh, T.-Y. J. Org. Chem., in press.

$$
\overbrace{42}^{2} \mathrm{SiMe}_{3}
$$

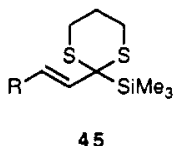

45

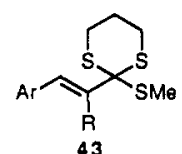

43<smiles>C=C/C=C(/[AsH3])C[13CH3]</smiles>

46

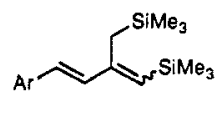

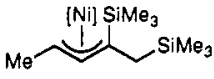

47
$44(E / Z=31-38 / 62-69)$

cyclopropyl Grignard reagent with trimethylsilyl-substituted dithioacetals (cf. eq 9). The reactions are stereospecific, and the yields are good. ${ }^{20 \mathrm{~b}}$

A Possible $\beta-\mathrm{Me}_{3} \mathrm{Sn}$ Elimination. Interestingly, the reactions of benzylic dithioacetals with $\mathrm{Me}_{3} \mathrm{SnCH}_{2} \mathrm{MgI}$ in the presence of a catalytic amount of $\mathrm{NiCl}_{2}\left(\mathrm{PPh}_{3}\right)_{2}$ afford styrenes in $62-84 \%$ yields (eq 12). No trace amount of vinylstannanes or allylstannanes has been detected. ${ }^{26}$ It has been established that no transmetalation of vinylstannanes occurs under the reaction conditions. The active species for the dithioacetal cross-coupling reactions has been shown to be the " $\mathrm{Me}_{3} \mathrm{SnCH}_{2}$ " moiety, and the reaction may proceed via a pathway similar to that shown in Scheme II. $\beta$-Elimination of the $\mathrm{Me}_{3} \mathrm{Sn}$ group apparently occurs preferentially to give styrene. The actual mode of such an elimination step, however, is not clear. Either a concerted elimination mechanism or a stepwise radical process via the homolytic cleavage of the carbon-nickel bond from 48 followed by the elimination of a $\mathrm{Me}_{3} \mathrm{Sn}$ radical would yield the same product. ${ }^{27}$ An alternative possibility would be the elimination of a $\mathrm{Me}_{3} \mathrm{SnS}$ moiety from a $\beta$-sulfurated organotin species $49 .^{26}$

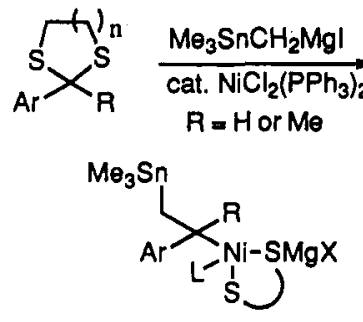

48<smiles>C=C([Ge])[Te]</smiles>

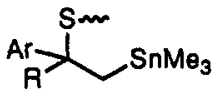

49
Tandem Reactions. As mentioned previously, simple aliphatic dithioacetals are inert toward Grignard reagents under similar conditions. A search for the activation of such a dithioacetal moiety has led to the development of the tandem coupling of bis(dithioacetals). ${ }^{28}$ For example, the reaction of bis(dithioacetal) 50 with $\mathrm{Me}_{3} \mathrm{SiCH}_{2} \mathrm{MgCl}$ in the presence of a nickel catalyst produces dienes 51 in $50-70 \%$ yields with the $Z$ isomers predominating $(Z / E \geq 6 / 1)$. The success of this tandem reaction suggests the regioselective formation of the apparent intermediate $\mathbf{5 2}$.<smiles>[Te]C1(CC2SCCS2)SCCCS1</smiles>

50<smiles>C[SiH3]C=CC=C(Br)C[SiH3]</smiles>

51<smiles>C[SiH2]C/C([Al])=C\C1SCCS1</smiles>

52
Nickel-Catalyzed Geminal Dialkylation

Geminal Dimethylation of Allylic Dithioacetals. Like many other transition-metal-catalyzed reactions,

(26) Shi, X.; Luh, T.-Y. Organometallics 1990, 9, 3019.

(27) Curran, D. P.; van Elburg, P. A.; Giese, B;; Gilges, S. Tetrahedran Lett. 1990, 31, 2861 and references therein.

(28) Wong, K.-T.; Luh, T.-Y., manuscript in preparation. 
the nickel-catalyzed coupling reaction of dithioacetals is very sensitive to the steric environment. When MeMgI is employed, the cross-coupling reactions of simple allylic dithioacetals $\mathbf{4 0}$ lead primarily to geminal dimethylation products 53 in addition to a small amount of butadienes $54 .{ }^{25}$ The formation of butadienes can be suppressed when bidentate ligands such as dppe or dppp are used in place of $\mathrm{Ph}_{3} \mathrm{P}$ in the catalyst. The involvement of an 18-electron $\pi$-allyl intermediate $\mathbf{5 5}$ is likely to enhance the reductive elimination process, resulting in the facile formation of the second carboncarbon bond. ${ }^{29}$ The reactions are regiospecific, only geminal dimethylation products being obtained. This dimethylation reaction provides a unique procedure for the conversion of an $\alpha, \beta$-unsaturated carbonyl equivalent into the corresponding geminal dimethyl group.<smiles>CC([Mg])C=C[Al]</smiles>

53

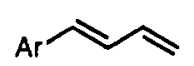

54

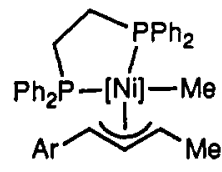

55
An extension of this reaction to allylic orthothioesters $43(R=H)$ yields the trimethylated product 56. To our surprise, the isolation of $\mathbf{5 7}$ indicates that the first methyl group is introduced at C-3. The presence of a substituent at $C-2$ in $43(R=$ alkyl) would allow the coupling to be less selective; a mixture of 56 and 58 is generally obtained. ${ }^{25 b}$<smiles>CC(C)=C(P)C(C)C</smiles><smiles>[Mg]C([Al])C=C1SCCCS1</smiles><smiles>[R]/C(=C\[Tl])C(C)(C)C</smiles>

58

Geminal Dialkylation of Benzylic Dithioacetals. Other desulfurative geminal dialkylations of benzylic dithioacetals are also possible. Thus, the geminal diethyl products 59 have been isolated in $52-62 \%$ yields. Bisallylation of benzophenone and fluorenone dithioacetals gives $60 .{ }^{25 b}$ Surprisingly, attempts to dimethylate benzylic substrates were unsuccessful; styrenes are always the major products. However, the presence of an ortho amino group (e.g., 61) causes a dramatic change; e.g., 2-isopropylaniline 62 is obtainable in $60-70 \%$ yields. ${ }^{25 \mathrm{~b}}$ This neighboring amino moiety may enhance the rate of reductive elimination. An ortho hydroxyl group in the phenolic analogues, on the other hand, shows only a very weak neighboring effect; the corresponding styrenes were isolated as the predominant products. ${ }^{25 c}$<smiles>CCC(Br)CC</smiles><smiles>C=CCC([Al])([Al])CC=C</smiles>

59<smiles>[X]c1cccc(C2SCCCS2)c1N</smiles>

61

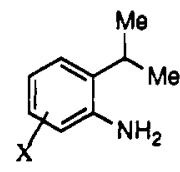

62

W(CO) $)_{6}$-Mediated Desulfurdimerization of Dithioacetals

Thioketones react with a carbene precursor such as diazoalkane to give the corresponding 1,3-dithiolanes

(29) (a) Kurosawa, H.; Ohnishi, H.; Emoto, M.; Kawasaki, Y.; Murai, S. J. Am. Chem. Soc. $1988,110,6272$. (b) Kurosawa, H.; Ohnishi, H.; Emoto, M.; Chatani, N.; Kawasaki, Y.; Murai, S.; Ikeda, I. Organometallics $1990,9,3038$.

(eq 13). ${ }^{30}$ The reverse reaction considering a dithiolane as a carbene synthon would be useful in organic synthesis. Metal carbonyls are well documented to desulfurdimerize benzylic thioethers ${ }^{31 a}$ or thioketones. ${ }^{31 b, c}$ Our initial study has shown that the reaction of 63 with $\mathrm{Mo}(\mathrm{CO})_{6}$ in refluxing THF gives a mixture of fluorene and bifluorenylidene 64 (eq 14). ${ }^{32}$ The formation of 64 suggests that a carbene-like intermediate may be involved and can be considered as the reverse reaction shown in eq 13.

$$
\left.\mathrm{CH}_{2} \mathrm{~N}_{2}+{ }_{\mathrm{Ar}}^{\mathrm{Ar}}\right\rangle=\mathrm{S} \longrightarrow\left\langle\mathrm{S}_{\mathrm{Ar}}^{\mathrm{S}}\right.
$$
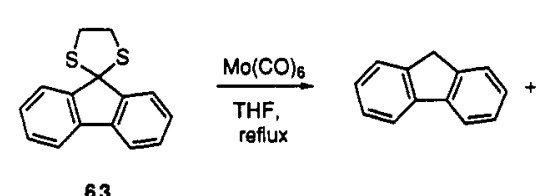

63

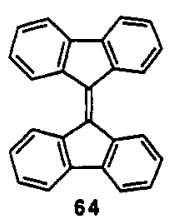

(14)
The group 6 metal carbonyl mediated $\mathrm{C}-\mathrm{S}$ bond cleavage reaction has been established to occur via a free-radical mechanism. ${ }^{31 a, d}$ Therefore, the reduced product may arise from a hydrogen atom abstraction reaction from the solvent by a radical species. Halobenzenes have been shown to be an excellent solvent for the metal carbonyl promoted coupling of two in situ generated radical species. ${ }^{33}$ Thus, upon treatment with $\mathrm{W}(\mathrm{CO})_{6}$ in refluxing chlorobenzene, dithiolanes undergo desulfurdimerization reactions to give dimeric olefins in 45-97\% yields (eq 15). ${ }^{34,35}$ Dithiolanes derived from diaryl or alkyl aryl ketones work beautifully. Even adamantanone and diphenylketene dithioacetals desulfurdimerize to give biadamantylidene and tetraphenylbutatriene, respectively, in $71 \%$ yields. Functional groups such as ether, ester, nonbenzylic halide, acetal, and (aliphatic) thioether are stable under the reaction conditions. On the other hand, the presence of an acidic proton such as found in carboxylic acids or alcohols inhibits the dimerization reaction. The extension of this reaction to the synthesis of aryl-substituted poly(phenylenevinylenes) 65 has been performed (eq 16). ${ }^{36}$

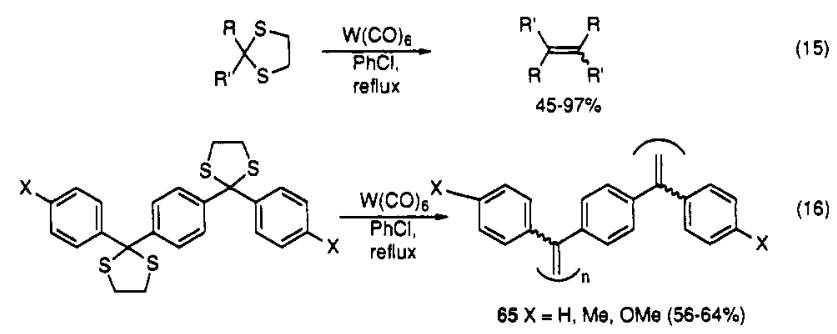

(30) (a) Schönberg, A.; König, B.; Einger, E. Chem. Ber. 1967, 100, 767. (b) Ohno, A.; Ohnishi, Y.; Fukuyama, M.; Tsuchihashi, G. J. Am. Chem. Soc. 1968, 90, 7038

(31) (a) Ng, C.-T.; Wang, X.-j.; Luh, T.-Y. J. Org. Chem. 1988, 53, 2536. (b) Alper, H. J. Organomet. Chem. 1974, 73, 357. (c) Alper, H,; Park, H.-N. J. Org. Chem. 1977, 42, 3522. (d) Ng, C.-T.; Luh, T.-Y.J. Organomet. Chem. 1991, 412, 121.

(32) Luh, T.-Y.; Wong, C. S. J. Org. Chem. 1985, 50, 5413.

(33) Luh, T.-Y.; Lee, K. S.; Tam, S. W. J. Organomet. Chem. 1983, $248,211$.

(34) (a) Yeung, L. L.; Yip, Y. C.; Luh, T.Y. J. Chem. Soc., Chem. Commun. 1987, 981. (b) Yeung, L. L.; Yip, Y. C.; Luh, T.-Y. J. Org. Chem. 1990, 55, 1874.

(35) Wong, C. S.; Leung, W. S.; Yeung, L. L.; Luh, T.-Y. J. Organomet. Chem. 1986, 307, C49.

(36) Kuo, C.-H.; Luh, T.-Y. J. Chem. Soc., Chem. Commun. 1990, 
The W(CO) $)_{6}$-promoted intramolecular desulfurdimerization (eq 17) has been employed for the synthesis of bifluorenylidene-hinged crown ethers $66 .{ }^{37}$ The first chiral bifluorenylidenes 67 were obtained by a similar reaction of two fluorene moieties linked with a chiral bridge. ${ }^{37 b, c}$ No dilution technique is required for this intramolecular reaction. Based on this procedure, $(Z)-2,2^{\prime}$-disubstituted bifluorenylidenes 68 are conveniently prepared. ${ }^{37}$
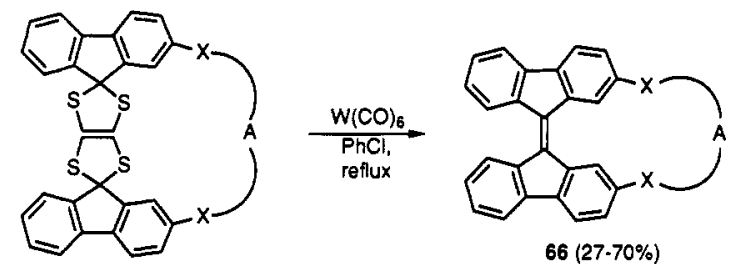

(17)

$X=-0$ - or $\mathrm{CO}_{2} ; A=-\left(\mathrm{CH}_{2}\right)_{n}-($ where $n=2$ to 11$)$ or $-\left(\mathrm{CH}_{2} \mathrm{CH}_{2} \mathrm{O}\right)_{n} \mathrm{CH}_{2} \mathrm{CH}_{2}$ - (where $\mathrm{n}=0$ to 4$)$

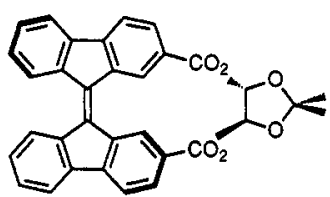

67

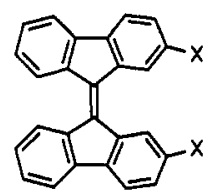

68
Mechanism. The mechanism of the $\mathrm{W}(\mathrm{CO})_{6}$-mediated desulfurdimerization reactions of dithiolanes 69 has been shown to proceed via a thioketone intermediate 71 (eq 18). ${ }^{37 \mathrm{c}}$ The first carbon-sulfur bond is cleaved to generate a radical intermediate 70 . Fragmentation of 70 gives 71 and ethylene as the organic products. Desulfurdimerization of thioketone promoted by metal carbonyls to give dimeric olefins has previously been established. ${ }^{31 b, c, 37 c}$

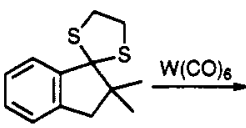

69

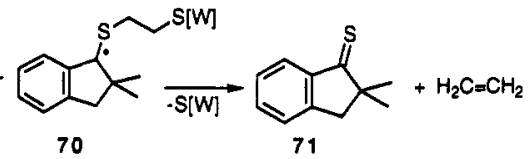

71
The $\mathrm{W}(\mathrm{CO})_{6}$-mediated reactions of 1,3-dithiane derivatives further support the involvement of a radical intermediate like 70. Treatment of the fluorenone dithiane with $\mathrm{W}(\mathrm{CO})_{6}$ in refluxing chlorobenzene gives 64 and trimeric terfluorene 72 in $28 \%$ and $54 \%$ yields, respectively (eq 19). ${ }^{38}$ The formation of 72 apparently involves a reduction process via an intramolecular 1,5hydrogen atom transfer process. ${ }^{39}$ Accordingly, 74 generated from 9-fluorenyl radical 73 may be the key intermediate leading to 72 . The formation of 72 seems to be unique to substrates having the fluorenyl moiety. The benzophenone derivative, on the other hand, yields 75-77 (eq 20). ${ }^{38}$ Generation of the reduced products 76 and $\mathbf{7 7}$ is also consistent with the proposed radical mechanism.

The extension of the desulfurdimerization to the coupling of a benzylic dithiolane moiety with a thioamide group has been used as one of the key steps in a synthesis of functionalized benzazepines (eq 21). ${ }^{40}$

(37) (a) Nz, D. K. P.; Luh, T.-Y. Tetrahedron Lett. 1988, 29, 5131. (b) Wang, X.-j.; Luh, T.-Y.J. Org. Chem. 1989, 54, 263. (c) Yip, Y. C.; Wang, X.-j.; Ng, D. K. P.; Mak, T. C. W.; Chiang, P.; Luh, T.-Y.J. Org. Chem. $1990,55,1881$.

(38) Kuo, C.-H.; Luh, T.-Y.; Cheng, M.-c.; Peng, S.-m. J. Chin. Chem. Soc. $1991,38,35$

(39) Freidlina, R. Kh.; Terent'ev, A. B. Acc. Chem. Res. 1977, 10, 9.

(40) (a) Fang, F. G.; Danishefsky, S. J. Tetrahedron Lett. 1989, 30 2747. (b) Fang, F. G.; Maier, M. E.; Danishefsky, S. J.; Schulte, G. J. Org. Chem. 1990, 55, 831 .

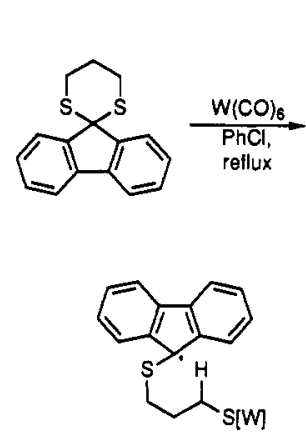

73
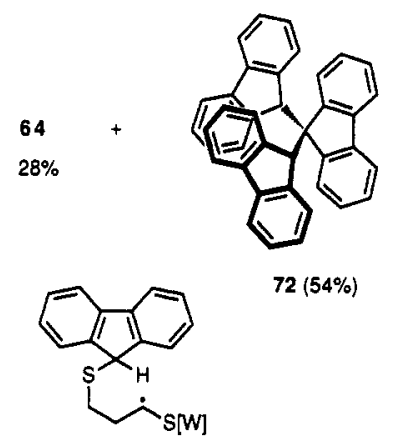

$72(54 \%)$

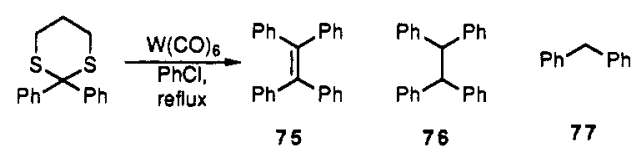
$24 \% \quad 50 \% \quad 4 \%$<smiles>COC(=O)C1(c2cc3c(cc2CCN2C(=O)c4c(ccc(OC)c4OC)C2=S)OCO3)CCSC1</smiles>

\section{Miscellaneous Reactions}

The open-chain dithioacetal functionality reacts with carbon nucleophiles in the presence of a thiophilic Lewis acid catalyst (eq 22).41 High diastereoselectivity has been found in this coupling reaction (eq 23). ${ }^{42}$ The reaction of allylstannane with dithioacetal is mediated by $\mathrm{GaCl}_{3}$ to yield homoallyl sulfides (eq 24). ${ }^{43}$ The $\mathrm{Cu}(\mathrm{I})$-catalyzed intramolecular displacement of a $\gamma$ dithioacetal moiety with an enolate anion generated in situ constitutes a useful procedure for cyclopropanation. ${ }^{44} \mathrm{Ag}(\mathrm{I})^{45 \mathrm{a}}$ and $\mathrm{TiCl}_{4}{ }^{45 \mathrm{~b}}$ have been employed to activate orthothioesters for the electrophilic substitution.

$$
\text { Mes=mesityl }
$$

Other synthetic applications of the dithioacetal functionality have been sporadically investigated. Partial reduction of dithioacetals can be achieved by electrochemical methods ${ }^{46}$ or by using a stoichiometric amount of $n-\mathrm{Bu}_{3} \mathrm{SnH}^{47}$ or $\left(\mathrm{Me}_{3} \mathrm{Si}\right)_{3} \mathrm{SiH} .{ }^{48}$ The tin hy-

(41) (a) Trost, B. M.; Murayama, E. J. Am. Chem. Soc. 1981, 103, 6529. (b) Ohshima, M.; Muraikami, M.; Mukaiyama, T. Chem. Lett. 1985, 1871 and references therein.

(42) Mori, I.; Bartlett, P. A.; Heathcock, C. H. J. Org. Chem. 1990, 55, 5966.

(43) Saigo, K.; Hashimoto, Y.; Kihara, N.; Hara, K.-i.; Hasegawa, M. Chem. Lett. 1990, 1097.

(44) (a) Cohen, T.; Myers, M. J. Org. Chem. 1988, 53, 457. (b) Ramig, K.; Bhupathy, M.; Cohen, T. J. Am. Chem. Soc. 1988, 110, 2678.

(45) (a) Posner, G. H.; Asirvatham, E.; Hamill, T. G.; Webb, K. S. J. Org. Chem. 1990, 55, 2132. (b) Stutz, P.; Stadler, P. A. Helv. Chim. Acta $1972,55,75$.

(46) Itter, N. S.; Steckhan, E. Tetrahedron 1987, 43, 2475.

(47) (a) Gutierrez, C. G.; Stringham, R. A.; Nitasaka, T.; Glasscock, K G. J. Org. Chem. 1980, 45, 2893. (b) Yadav, V. K.; Fallis, A. G. Tetrahedron Lett. 1988, 29, 897; 1989, 30, 3283. 
dride induced carbon-sulfur bond cleavage reaction has been used to generate a sulfur-stabilized radical that can add to a double bond, resulting in carbon-carbon bond formation. ${ }^{49}$ Treatment of 1,3-dithiolanes with alkyllithium leads to mercaptans..$^{50}$ The carbon-sulfur bond in acyclic dithioacetals can be displaced by heteroatomic nucleophiles, which is a useful reaction in heterocycle syntheses..$^{51}$ The chemistry of ketene dithioacetals has been extensively studied. ${ }^{52}$ Reductive metalation of ketene dithioacetals and subsequent reaction with carbon electrophiles provides a useful entry for carbon-carbon bond formation. ${ }^{52 c}$ The elimination of one of the carbon-sulfur bonds in acyclic dithioacetals has been used frequently in the preparation of vinyl sulfides. ${ }^{63}$

(48) Arya, P.; Samson, C.; Lesage, M.; Griller, D. J. Org. Chem. 1990, 55,6248 .

(49) (a) Tsai, Y.-M.; Chang, F.-C.; Huang, J.; Shiu, C.-L. Tetrahedron Lett. 1989, 30, 2121. (b) Tsai, Y.-M.; Ke, B.-M.; Lin, C.-H. Tetrahedron Lett. 1990, 31, 6047 and references therein.

(50) Wilson, S. R.; Georgiadis, G. M.; Khatri, K. N.; Bartmess, J. E J. Am. Chem. Soc. 1980, 102, 3577.

(51) For example: Nicolaou, K. C.; Prasad, C. V. C.; Hwang, C.-K.; Duggan, M. E.; Veale, C. A. J. Am. Chem. Soc. 1989, 111, 5321.

(52) For reviews on ketene dithioacetals, see: (a) Kolb, M. Synthesis 1990, 171. (b) Junjappa, H.; Ila, H.; Asokan, C. V. Tetrahedron 1990, 46, 5423. (c) Cohen, T.; Bhupathy, M. Acc. Chem. Res. 1989, $22,152$.

(53) For examples: (a) Bartels, B.; Hunter, R.; Simon, C. D.; Tom. linson, G. D. Tetrahedron Lett. 1987, 28, 2985. (b) Denis, T. N.; Krief, A. Tetrahedron Lett. 1982, 23, 3407. (c) Rodriguez, A. D.; Nickon, A. Tetrahedron 1985, 41, 4443.

\section{Conclusions}

With the aid of various thiophilic reagents or catalysts, carbon-sulfur bonds in benzylic or allylic dithioacetals are readily replaced by carbon-carbon bond(s). The nickel chemistry and tungsten chemistry, together with other possibilities described in this Account, clearly demonstrate new types of useful synthetic reactions. The versatility of the dithioacetal functionality, at one time thought to be stable and not very useful, has now increased. Rather complicated reactions involving the carbonyl group (e.g., in vinylsilane synthesis) can now be simplified. The mechanistic insight of these reactions (e.g., the sulfur tandem ancillary effect) can pave the way to make predictions of other opportunities for new transformations, and room for new inventions emanating from the present research abounds. Because the chemistry of organosulfur compounds is so rich, such a prospect provides a major impetus for continuing the investigation of novel carbon-carbon bond formation methodologies starting from dithioacetals.

I thank all my collaborators, whose names are mentioned in the references, for their invaluable contributions, which made all of this possible. Thanks are also due to Professors J.-M. Fang, T.-L. Ho, and Y.-M. Tsai and Drs. W. S. Price and D. Sedney, who kindly read the manuscript and offered valuable suggestions. This work has been supported by the National Science Council of the Republic of China and the Croucher Foundation of Hong Kong. 